\title{
PRE-TREATMENT OF OLIVE OIL MILL WASTEWATERS BASED ON SOLAR MANAGEMENT TECHNIQUES: AN INTEGRATED RATIONAL APPROACH Maha A. Tony ${ }^{1 *}$, Aghareed M. Tayeb ${ }^{2}$
}

\author{
${ }^{1}$ Basic Engineering Science Department, Faculty of Engineering, Minoufiya University, Shbin El- \\ koum, Minoufiya, Egypt \\ ${ }^{2}$ Chemical Engineering Department, Faculty of Engineering, Minia University, Minia, Egypt \\ *Corresponding author: Tel: +2 0482221549, Fax: +2 0482235695, E-mail: \\ maha_tonyl@yahoo.com
}

\begin{abstract}
:
Wastewater contaminated with olive oil which simulates the olive oil mills has been treated by means of Advanced Oxidation Processes (AOPs). The $\mathrm{Fe}(\mathrm{II}) / \mathrm{H}_{2} \mathrm{O}_{2}$ system (Fenton's reagent), $\mathrm{Fe}(\mathrm{II}) / \mathrm{H}_{2} \mathrm{O}_{2} / \mathrm{UV}$ system (solar-photo-Fenton's reagent) and the UV-photolysis were applied. A synthetic wastewater generated by emulsifying olive oil and water was used. Experiments were carried out using a concentrating Parabolic Trough Reactor (PTR). Oil is readily degradable, the sunlight is captured by ferrioxalate which, in the presence of hydrogen peroxide, generates hydroxyl radicals that oxidizes organic molecules. In addition, the process efficiency is increased by using oxalic acid. Typical operating variables such $\left(\mathrm{H}_{2} \mathrm{O}_{2}\right.$ and $\left.\mathrm{Fe}(\mathrm{II})\right)$ exerted a positive influence on the treatment efficiency. The optimum working $\mathrm{pH}$ on the Fenton treatment was found to be in the range 2.5-3.0. Response Surface Methodology (RSM) based on the experimental design was applied to optimize the Fenton oxidation process.

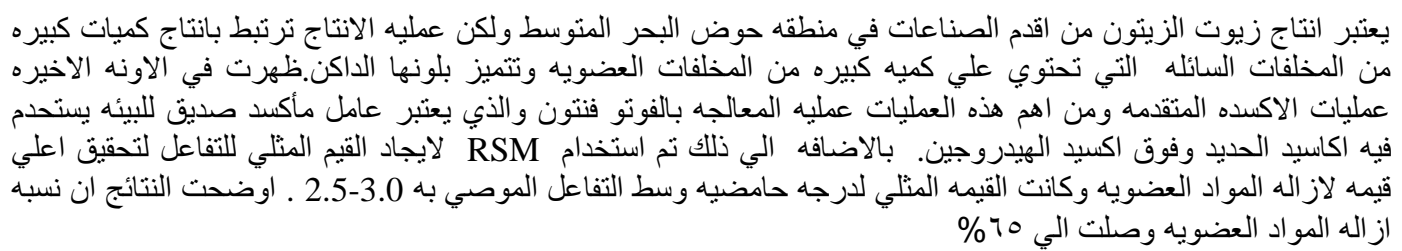

Keywords: Solar photo-catalysis, olive oil wastewater, Fenton's reagent, Response Surface Methodology

\section{1- INTRODUCTION}

Mediterranean Sea region is considered as the largest olive oil producer in the world. It is estimated that the annual world production of olive oil (black and white) and table olives is about $2.5 \times 10^{6}$ and $10^{6}$ tons, respectively [1]. Therefore, there is many foodstuff processing industry based on this olive oil extraction and table olive preparation which constitutes an important income source for Mediterranean countries. Consequently, there is high seasonal wastewater pollution potential from the olive oil mill waters. The annual olive oil mill wastewater generated in this region is estimated to be over $10^{7} \mathrm{~m}^{3}$ [2] which is considered the main waste product of this industry. The major importance for the companies that deal with this sector is subjected to the management of the liquid wastes generated in mills.

The uncontrolled improper disposal and treatment of such wastewater is a serious environmental problem as it contains high organic loads. It causes a potential threat to surface and groundwater. Accordingly, the presence of this waste in rivers decreases the dissolved oxygen content but increases the organic matter and $\mathrm{K}, \mathrm{Fe}, \mathrm{Zn}$ and $\mathrm{Mn}$ contents. Moreover, the environmental concern is mainly due to the decrease of the fish population [35].

As a result of the associated environmental problems and potential hazards, several olive oil mill wastewater treatment technologies have been developed aiming at the removal of the main toxic organic compounds prior to discharge. The development of environmentally satisfactory methods for disposal of this wastewater still remains a problem, although the degradation of the toxic compounds contained in this wastewater will certainly enhance the treatment quality of such waters. Many studies have been carried out in order to degrade such waste [6-9].

In recent years, AOPs (Advanced Oxidation Processes) has received increasing attention for the destruction of organic pollutants in waters and 
wastewaters. It is may be used either for the complete mineralization of all pollutants to carbon dioxide, water, and mineral salts [7]. Among those AOPs, photo-Fenton's reagent is effective treatment procedure which requires iron ions in the presence of hydrogen peroxide and UV radiation to produce the hydroxyl radicals. Photo-Fenton's reagent is one of the advanced oxidation technologies which is the most widely applied AOPs since it is effective in treating different kinds of wastewater. In addition to its efficiency, this technology has another important advantage: no dangerous or persistent by-products are formed as a consequence of the reduction of the oxidizing agent. This process is mainly consists of a mixture of hydrogen peroxide and iron (II) salts is added directly to the wastewater. Besides the oxidation carried out by the hydroxyl radicals generated by catalytic decomposition of hydrogen peroxide, the iron (III) ions generated during the oxidation stage promote the removal of other pollutants by coagulation and sedimentation [10-11]. Various investigations report successful removal of a wide range of organic pollutants from wastewater, and it appears that the applications of this novel means of reaction in environmental remediation and pollution prevention is unlimited [12-14]. PhotoFenton process is applied successfully for olive oil treatment $[2,8,10,15,16]$. Unfortunately, in the recent years only few papers have engaged on the solar photo-oxidation with Fenton oxidation of olive oil mills.

AOPs could be developed such that it uses sunlight as the UV light source, thus this processes will be highly appreciated. Egypt is well endowed with a high solar intensity. The annual global radiation is between 7 and 9 GJ m ${ }^{-2}$ [17]. There are many researches in Egypt applied this solar energy i.e. in the thermoelectric cooling, heating systems powered by a photovoltaic cells [18] however, it is not used and applied so far in the solar detoxification system.

The main aim of the present study is to describe the application of the solar photo-Fenton reagent

(ferrous salt plus hydrogen peroxide) to the mineralization of a synthetic olive oil wastewater emulsion which simulates the olive oil mill wastewater. The effect of the reaction operating conditions was investigated and the RSM methodology was used to maximize the removal rates.

\section{MATERIALS AND METHODS}

\subsection{Artificial Olive Oil-Wastewater}

Olive oil was used to prepare the synthetic olive oil-water emulsion as a model pollutant for performing the oxidation experiments. Sodium dodecyl sulphate $(\mathrm{C} 12 \mathrm{H} 25 \mathrm{Na} 4 \mathrm{~S})$ emulsifier was used to disperse the olive oil in water according to our previous investigation [14].

\subsection{Experimental Materials}

$\mathrm{Fe}^{2+}$ in Fenton's reagent $\left(\mathrm{Fe}^{2+} / \mathrm{H}_{2} \mathrm{O}_{2}\right)$ is prepared by making a solution from $\mathrm{Fe}^{2+}$ salt. $\mathrm{H}_{2} \mathrm{O}_{2}$ was obtained in liquid $\left(30 \%\right.$ of $\mathrm{H}_{2} \mathrm{O}_{2}$, wt) from a commercial supplier. For the purpose of the increment of the Fenton reagent process oxalic acid was added. Sulfuric acid is used for adjusting the $\mathrm{pH}$ of the sludge samples during conditioning.

\section{PARABOLIC TROUGH COLLECTORS (PTC)}

Parabolic trough collectors are made by bending a sheet of reflective material into a parabolic shape. A glass tube to reduce heat losses is placed along the focal line of the receiver as shown in Fig. (1). When the parabola is pointed towards the sun, parallel rays incident on the reflector are reflected onto the receiver tube.

\subsection{Methodology and Analytical Determinations:}

The experiments were performed in a batch mode test (Fig. 1) by connecting a feed/discharge vessel to the glass tubular reactor. The photo catalyst is added to the feed/discharge vessel after the $\mathrm{pH}$ of the effluent has been adjustment through the use of sulfuric acid (using a digital $\mathrm{pH}$-meter, model $\mathrm{pH}$ 206). Then, the solution is circulated through the tubular reactor at the required flow rate. In addition, a simulated photo-reactor was used to compare the effectiveness of using solar light with artificial UV light by using a UV lamp (450 $\mathrm{nm}$ wavelength). The COD of the remaining oil in the wastewater is used to calculate the amount of oil concentration left. An Epply black-and-White solarimeter, (model 8-48) was used to record the solar intensity during the solar photo-treatment experiments. The solar radiation during the experiments ranged from $950-1220 \mathrm{~W} / \mathrm{m}^{2}$, which is proffered to be obtained around the solar noon.

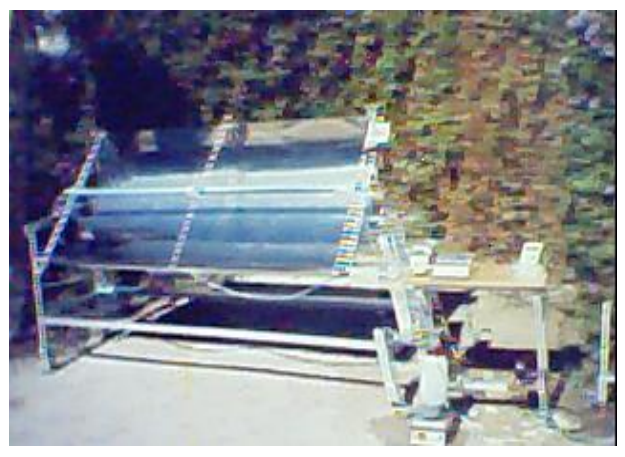




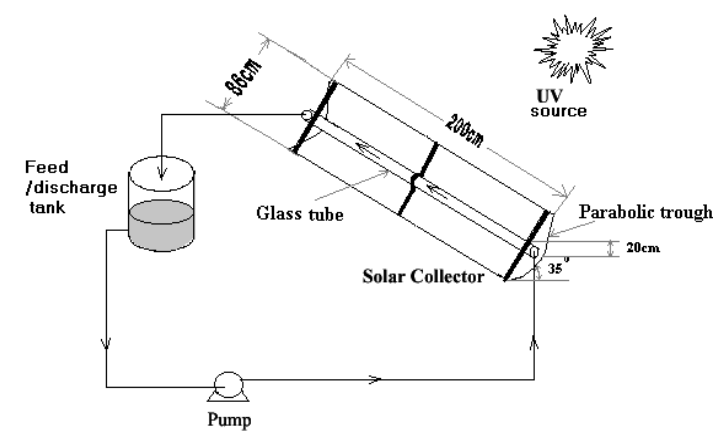

Fig. 1 photograph and scheme photo-chemical reactor (parabolic trough photo tubular reactor

\subsection{Experimental Design:}

Optimization by the response surface methodology (RSM) experimental design based on the Box-Behnken experimental design [19] was chosen to evaluate the combined effects of the three independent variables. The levels of the three independent variables, $\mathrm{Fe}^{2+}$ dosing, $\mathrm{H}_{2} \mathrm{O}_{2}$ dosing and oxalic acid initial concentration as $\mathrm{X}_{1}, \mathrm{X}_{2}$ and $\mathrm{X}_{3}$, respectively, during the solar-photo-Fenton reagent chosen for this study were optimized by the experimental plan. The statistical software package 'SAS' [20] were used to analyze the experimental design. Each factor in the design was studied at three different levels $(1-, 0,1)$ Table 1 . A set of 15 experiments were carried out. All variables were taken at a central coded value considered as zero. The minimum and maximum ranges of variables were investigated and the full experimental plan with respect to their values in actual and coded form is listed in Table 1. Upon completion of experiments, the maximum oil removal efficiency was taken as the dependent variable or response (C). An empirical second-order polynomial model for three factors was in the following form [19]:

$$
C=\beta_{o}+\sum \beta_{i} \mathrm{X}_{i}+\sum \beta_{i i} \mathrm{X}_{i}^{2}+\sum \sum \beta_{i j} \mathrm{X}_{i} \mathrm{X}_{j}
$$

\section{Results and discussions:}

\subsection{Effect of reaction time for different AOPs}

Reaction time effect on different AOPs namely solar photo-Fenton process, artificial UV source based photo-Fenton process and Fenton's reagent process were tested to determine an experimental condition for further research. In this study, we evaluated the efficiency of the Fenton process in terms of oil concentration removal. The doses for the reagent were: $\left[\mathrm{Fe}^{2+}\right]=190 \mathrm{mg} / \mathrm{L} ;\left[\mathrm{H}_{2} \mathrm{O}_{2}\right]=350 \mathrm{mg} / \mathrm{L}$ and the starting $\mathrm{pH}$ of the emulsion was 3 . In addition, the solution was circulated with a flow rate of $1025 \mathrm{ml} / \mathrm{min}$. For the solar radiated experiment the solar radiation is measured in Fig. 2. The results in
Fig. 2 demonstrated that pollutant was rapidly degraded by the solar based photo-Fenton's reagent, the reaction rate reached to $57 \%$ removal rate. Clearly, as reported in the literature [21] the reaction between the ferrous ions and hydrogen peroxide produced the $\cdot \mathrm{OH}$ radicals which played an important role in the oil degradation.

Those radicals attack these aromatic compounds opening the rings and producing reaction intermediates which are ultimately converted to harmless end products such as $\mathrm{CO}_{2}$ and $\mathrm{H}_{2} \mathrm{O}$ [14]. Based on the results, the reaction time for the solar photo-Fenton's treatment with batch reactor was determined to be $40 \mathrm{~min}$ for further experiments.

The combination of the solar energy with the photo-Fenton leads to the formation of additional hydroxyl radicals and recycling of ferrous catalyst by reduction of $\mathrm{Fe}$ (II) which accelerate the overall reaction [22]. The reaction rate enhanced with $10 \%$ removal efficiency than the artificial UV radiation is used. However, when the Fenton's reagent used alone achieved a COD reduction of $33 \%$. This illustrates that the role of the chemical reagent in the generation of more reaction hydroxyl intermediates, which resulted in enhanced degradation of the pollutants (Al Momani et al., 2007; [14, 23].

Table 1 Range and levels of natural and corresponded coded variables for RSM

\begin{tabular}{lcccccc}
\hline \multirow{2}{*}{$\begin{array}{c}\text { Variable } \\
(\mathbf{m g} / \mathbf{l})\end{array}$} & \multicolumn{2}{c}{ Symbols } & & \multicolumn{3}{c}{$\begin{array}{c}\text { Range and } \\
\text { levels }\end{array}$} \\
\cline { 2 - 3 } \cline { 6 - 8 } & Natural & Coded & & $\mathbf{- 1}$ & $\mathbf{0}$ & $\mathbf{1}$ \\
\hline $\mathrm{Fe}^{2+}$ & $\delta_{1}$ & $x_{1}$ & & 30 & 190 & 350 \\
$\mathrm{H}_{2} \mathrm{O}_{2}$ & $\delta_{2}$ & $x_{2}$ & & 350 & 650 & 950 \\
$\begin{array}{l}\text { Oxalic } \\
\text { acid }\end{array}$ & $\delta_{3}$ & $x_{3}$ & & 30 & 60 & 90 \\
\hline
\end{tabular}

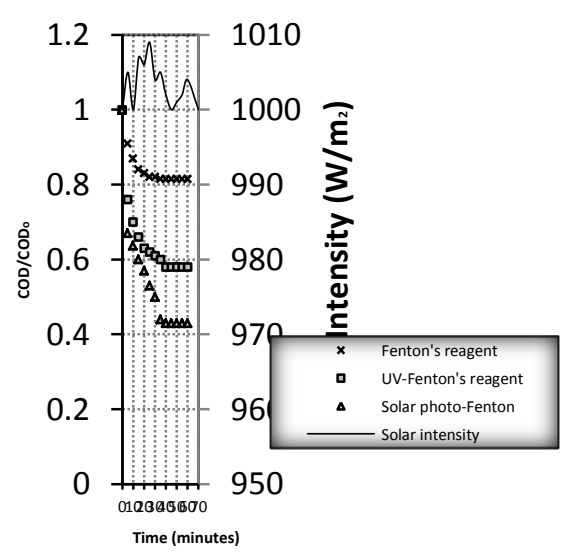

Fig. 2 Effect of reaction time on oil removal efficiencies for different AOPs 


\subsection{Effect of The initial $\mathrm{pH}$}

Photo-Fenton process has a typically sharp, preferred $\mathrm{pH}$ region in which it is optimally operated. $\mathrm{pH}$ affects the activity of both speciation of iron, and hydrogen peroxide decomposition, thus higher hydroxyl radical product yields in the $\mathrm{pH}$ range of $2-$

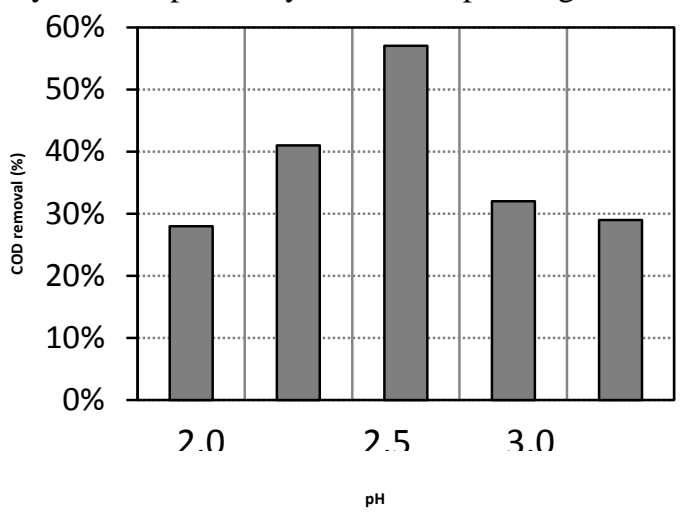

Fig.3 Effect of pH on oil solar photo-Fenton treatment

4 [24]. Moreover, controlling the $\mathrm{pH}$ in the acidic conditions can be easily removing the inorganic carbon which is scavenging the hydroxyl radical production. In order to assure the optium working $\mathrm{pH}, \mathrm{pH}$ of the emulsion was adjusted at different acidic values $(2.0,2.5,3.0)$ and left without any adjustment at 5.0, and in alkaline value (8.0). The doses for the reagent were: $\left[\mathrm{Fe}^{2+}\right]=190 \mathrm{mg} / \mathrm{L}$; $\left[\mathrm{H}_{2} \mathrm{O}_{2}\right]=350 \mathrm{mg} / \mathrm{L}$ and the circulation flow rate is $1025 \mathrm{ml} / \mathrm{min}$. Fig. 4 showed the effect of $\mathrm{pH}$ on the final COD removal efficiencies at 40 minutes of reaction time. Low $\mathrm{pH}$ between 2 and 3 has been found effective for Fenton's reagent, and best removal efficiency was obtained at $\mathrm{pH} 3$. These results agree with other studies on the oxidation of organic compounds in wastewaters, such as textile wastewater [25], landfill leachate, phenolic wastewater, oily-wastewater [14]. Further increase of $\mathrm{pH}$ showed drastic decrease of the soluble species, and the most irons precipitated. This fact agrees with authors's conclusions, who state that, below this $\mathrm{pH}$ concentration of $\mathrm{Fe}(\mathrm{OH})^{2+}$ declines and at higher $\mathrm{pH}$, $\mathrm{Fe}(\mathrm{III})$ precipitates as oxyhydroxides [14].

\subsection{Effect of Flow Rate}

The circulation flow rate was varied at 225, 525, 725,1025 and $1225 \mathrm{ml} / \mathrm{min}$ and the Fenton's reagent parameters are kept constant during the test: $\left(\mathrm{Fe}^{2+}\right.$ $=190 \mathrm{mg} / \mathrm{l}$ and $\mathrm{H}_{2} \mathrm{O}_{2}=350 \mathrm{mg} / \mathrm{l}$ at $\mathrm{pH} 3.0$ ). Fig. 6 shows the effect of flow rates on the \% reduction of oil removal. \% reduction of olive oil was found to be high for slow flow rates, since the residence time of the solution inside the photo-reactor tube was very high. Thus, for low residence time of the solution inside the cell, the \% removal of olive oil was found to be decreased as the flow rate is very high. Thus the very high flow rate is not enough to convert all the pollutants as the residence time in the reactor is low, thus the exposure time under solar radiation to produce the hydroxyl radicals is low. Moreover, the optimal flow rate reached at $(1025 \mathrm{ml} / \mathrm{min})$. These

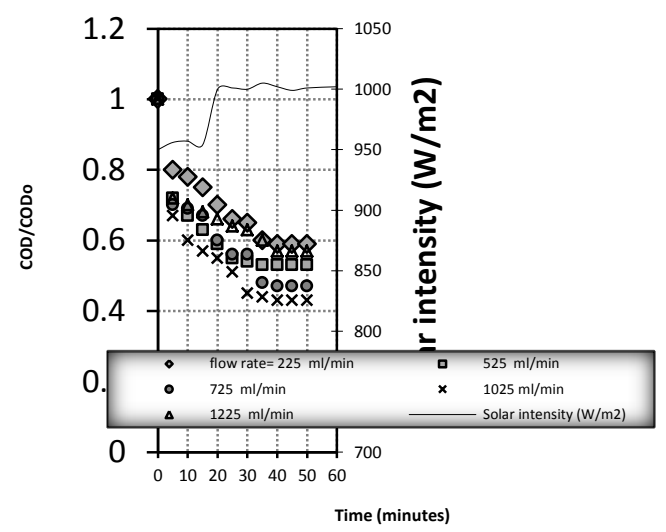

Fig. 4 Effect of circulation flow rate on the solar photoFenton treatment

results are in accordance with the previous investigation of Prabhakaran et al., [27].

\subsection{Effect Of Combination Solar Phto-Fenton's Reagent with Oxalic Acid}

As previously stated, the reaction between the ferrous ions and hydrogen peroxides initiated the hydroxyl radicals which are responsible of attacking the organic pollutants and degrading the, Increasingly, some authors state that $\mathrm{Fe}^{2+}$ and its oxalate complexes react with $\mathrm{H}_{2} \mathrm{O}_{2}$ efficiency to produce $\mathrm{OH}$ in water. The use of ferrioxalte as a source of $\mathrm{Fe}^{2+}$ for the photo-Fenton process, increase their possibilities since it produces additional degradation pathways, by generation of other (hydroxyl radical) radical species [28]. Therefore, the effect of the combined system oxalate/solar photo-Fenton was examined. Different oxalic acids concentrations are added to the solar Fenton reagent $\left(\mathrm{Fe}^{2+}=190 \mathrm{mg} / \mathrm{l}\right.$ and $\mathrm{H}_{2} \mathrm{O}_{2}=350 \mathrm{mg} / \mathrm{l}$ at $\mathrm{pH}$ 3.0). The results in Fig. 4 demonstrated that the presence of oxalic acid pos

That the degradation graph for treatment with and without oxalic acid gets the same general pattern, that is, that approximately $50 \%$ of the initial COD was degraded within the first 10 minutes, followed by a dramatic decrease in the conversion rate. However, the final COD reduction (\%) differs considerably depending on the process reagent added. The addition of oxalic acid increased the removal rate. The oxalate (oxalic acid) was added to convert part of $\mathrm{Fe}$ (III) present to the ferrioxalate complex under similar solar radiation as the other experiment. However, it is true until the concentration of is adopted at $60 \mathrm{mg} / \mathrm{l}$ (oxalate). Increasing the oxalate more than that optimal value is 
resulting in a precipitate of the salt in the solution. This agrees with the previous work of SafarzadehAmiri [28] in the destruction of toluene.

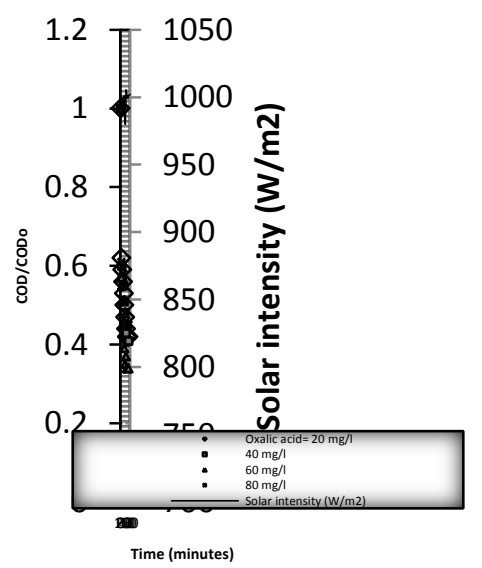

Fig. 5 Effect of combined system of solar photoFenton's reagent with oxalate

\subsection{Response Surface Plotting and Optimization of The Combined Treatment Based on The Pollutant Removal}

Many parameters might affect the efficiency or degradation of photo-Fenton, $\mathrm{H}_{2} \mathrm{O}_{2}$ and $\mathrm{Fe}^{2+}$ doses might affect the efficiency of the process (Torrades et al., 2003). In fact, these parameters are taken into account. Moreover, as seen above, the presence of oxalic acid positively influence the treatment, thus, it is also taken into consideration. The response surface methodology based on the experimental design is used to optimize such parameters $\left(\mathrm{H}_{2} \mathrm{O}_{2}, \mathrm{Fe}^{2+}\right.$ and oxalic acid doses) at a constant $\mathrm{pH}$ value (3.0). According to Box-Behnken factorial design, fifteen sets of experimental data were used in the numerical analysis and the relation between the experimental and predicted data are shown in Fig. 6. The experimental data collected was analysed by performing the analysis of variance (ANOVA) using the Statistical Analysis System (SAS) and fitted with the following second-order polynomial model:

$$
\begin{aligned}
C(\%) & =53-0.25 x_{1}-24.62 x_{1}^{2}-3.38 x_{2}+0.5 x_{1} x_{2}-17.38 x_{2}^{2} \\
& +1.38 x_{3}+16 x_{1} x_{3}+2.75 x_{2} x_{3}-7.88 x_{3}^{2}
\end{aligned}
$$

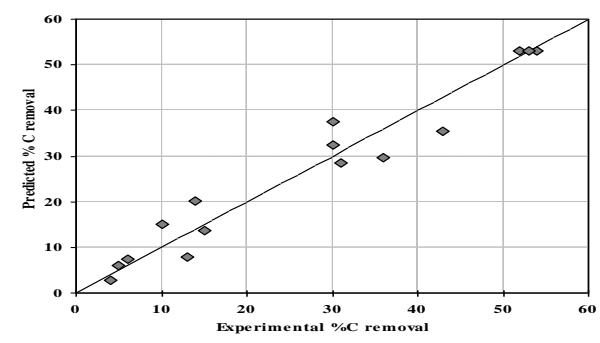

Fig.6 Regression plot of measured data against predicted values from the second-order response surface model describing \% COD removal by solar photo-Fenton oxidation, $\left(R^{2}=0.95\right)$

Mathematica software (V 5.2.) and response surface analysis were used to determine optimum conditions of the operating variables in the combined Fenton reaction system. The maximum COD removal efficiency $(\mathrm{C})$ is $53 \%$, whereas maximum values of the process variables in coded values given as follows: $X_{1}=0.026, X_{2}=-0.0891$ and $X_{3}=0.098$. Accordingly, actual doses of $\mathrm{Fe}^{2+}, \mathrm{H}_{2} \mathrm{O}_{2}$ and oxalic acid are 194, 677 and $63 \mathrm{mg} / \mathrm{l}$, respectively.

Fig. 7 illustrates the response under the coded variables of $\mathrm{Fe}^{2+}, \mathrm{H}_{2} \mathrm{O}_{2}$ and oxalic acid. It can be seen from Fig. 7a that a significant enhancement of $\mathrm{C}$ reduction efficiency is observed when the $\mathrm{H}_{2} \mathrm{O}_{2}$ concentration was increased. However, at higher concentrations of $\mathrm{H}_{2} \mathrm{O}_{2}$ the reduction rate was negatively affected. Thus, an excess of $\mathrm{H}_{2} \mathrm{O}_{2}$ does not mean a continuous increase in $\mathrm{C}$ removal of the olive oil removal. Similarly, the $\mathrm{C}$ reduction in percentage increased with increasing the $\mathrm{Fe}^{2+}$ concentration to a certain limit. Clearly, there is an optimal dosage for both $\mathrm{Fe}^{2+}$ and $\mathrm{H}_{2} \mathrm{O}_{2}$ concentrations. In the similar way, the $3 \mathrm{D}$ surface and the corresponding contour plotted in Fig. $7 b$ shows that the combination of $\mathrm{Fe}^{2+}$ concentration and oxalic acid has significant effects on $\mathrm{C}$ removals. Fig. $7 \mathrm{c}$ demonstrates that the increase in $\mathrm{pH}$ with the increase in $\mathrm{H}_{2} \mathrm{O}_{2}$ concentration enhances the efficiency of $\mathrm{C}$ reduction in a certain region; beyond that region the less reduction of $\mathrm{C}$ removal is observed. Therefore, the optimization of the $\mathrm{Fe}^{2+}$ and $\mathrm{H}_{2} \mathrm{O}_{2}$ concentrations as well as oxalic acid was conducted to achieve the highest $\mathrm{C}$ removal from the statistical point of view.

A validation of the model and regression equation was done by taking the actual doses of $\mathrm{Fe}^{2+}$, $\mathrm{H}_{2} \mathrm{O}_{2}$ and oxalic acid in the experiment. The predicted response for COD removal was 53\% and the actual response was $54 \%$, which thus proves the validity. This clearly demonstrated the effectiveness of the model to optimise the combined Fenton reaction in olive oil wastewater treatment. The model is highly significant as the P-value is less than 0.05 [19], the probability value is 0.0128 with a Fisher Ftest is 9.088. The high correlation coefficient $\left(\mathrm{R}^{2}\right)$ of 0.94 demonstrates how well the model fits the experimental data.

In order to assure the possibility of the process in the solar based treatment another experiments was conducted using the solar photo-Fenton's reagent with optimum reagent and oxalic acid doses. The COD removal under those conditions reached to $65 \%$, thus the process is highly recommended at the optimum conditions using the solar energy techniques. 
(a)

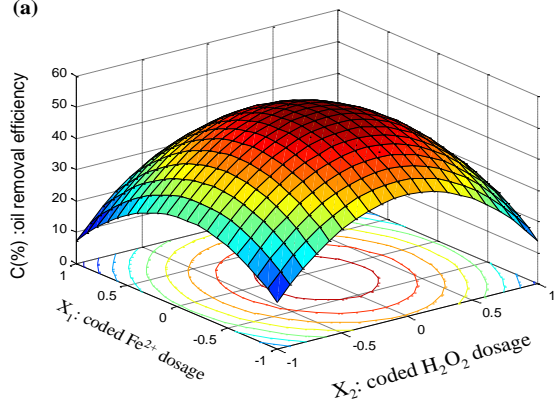

(b)

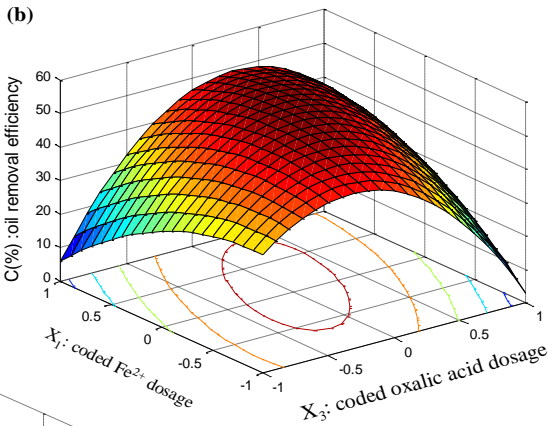

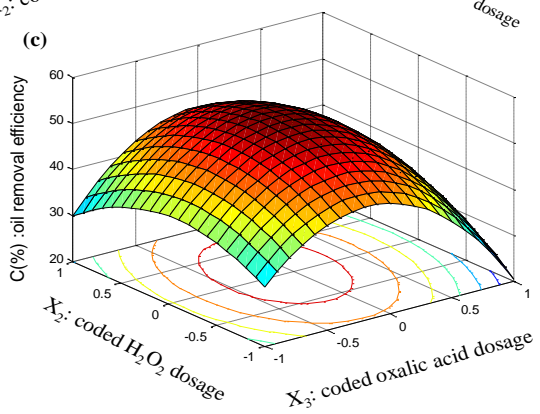

Fig. 7 Surface and contour plot for optimising photo-Fenton reaction in olive oil wastewater treatment: (a) coded Fe ${ }^{2+}$ and $\mathrm{H}_{2} \mathrm{O}_{2}$ vs. predicted $\mathrm{C}$ removal efficiency; (b) coded $\mathrm{Fe}^{2+}$ and oxalic acid vs. predicted $\mathrm{C}$ removal efficiency; (c) coded $\mathrm{H}_{2} \mathrm{O}_{2}$ and oxalic acid vs. predicted $\mathrm{C}$ removal efficiency.

\section{4- CONCLUSION}

This study focused on using AOPs based on solar energy as a potential candidate to achieve mineralization of oily wastewater. The photoFenton process $\left(\mathrm{Fe}^{2+} / \mathrm{H}_{2} \mathrm{O}_{2}\right)$ was conducted for synthetic olive oil wastewater which simulates the olive oil mill wastewater. The experimental study was carried out in a solar parabolic trough collector reactor at different flow rates and various $\mathrm{pH}$ values. The results of the study reported that COD reduction is almost dependent on the amount of the reagent added. In addition, the presence of oxalic acid showed a pronounced effect for the COD removal. Moreover the comparison between different AOP (Fenton's reagent, UV-Fenton, Solar photo-Fenton) was conducted. The study highlighted that the solar photo-Fenton set up is the best effect of COD reduction

\section{REFERENCES}

[1] Mantzavinos, D., Kalogerakis, N., Treatment of olive mill effluents Part I. Organic matter degradation by chemical and biological processes - an overview, Environment International 31, 2005, 289- 295.

[2] Rosa, S.D., Giordano, G., Granato, T., Katovic, A., Siciliano, A., Treipicchio, F., Chemical Pretreatment of Olive Oil Mill Wastewater Using a Metal-Organic Framework Catalyst, J. Agric. Food Chem. 2005, 53, 8306-8309.
[3] Cabrera, F., Toca, G.C., Diaz, E., Arambarri, D.E.P., Acid mine-water and agricultural pollution in a river skirting the Donana national park (Guardi amar river, southwest Spain). Water Res. 18, (12), 1984, 1469-1482.

[4] Martin, A., Borja, R., Chica, A., Kinetic study of an anaerobic fluidized bed system used for the purification of fermented olive mill wastewater. J. Chem. Tech. Biotechnol., 56, 1993, 155-162.

[5] Gharshall, N., Production of single cell protein from olive mill wastewater by yeasts. Environmental Technology, 14, 1993, 391-395.

[6] Davies, L.C., Vilhena, A.M., Novais J.M., Martins-Dias, S., Olive mill wastewater characteristics: modelling and statistical analysis, Grasas y Aceites, 55 (3), (2004), 233241

[7] Atanassova, D., Kefalas, P., Petrakis, C., Mantzavinos, D., Kalogerakis, N., Psillakis, E., Sonochemical reduction of the antioxidant activityof olive mill wastewater, Environment International 31, 2005, 281- 287

[8] Canizares, P., J. Lobato, R. Paz, M.A. Rodrigo, C. Saez, Advanced oxidation processes for the treatment of olive-oil mills wastewater, Chemosphere 67, 2007, 832-838

[9] Khatib, A., Aqra, F., Yaghi, N., Subuh, Y., Hayeek, B., Musa, M., Basheer, S., Sabbah, I., Reducing the Environmental Impact of Olive 
Mill Wastewater, American Journal of Environmental Sciences 5 (1), 2009, 1-6.

[10] Rivas, F.J., Beltran, F.J., Gimeno, O., Frades, J., Treatment of olive oil mill wastewater by Fenton's reagent. J. Agric. Food. Chem. 49, 2001, 1873-1880.

[11] Vlyssides, A.G., Loukakis, H.N., Karlis, P.K., 2004. Olive mill wastewater detoxification by applying $\mathrm{pH}$ related Fenton oxidation process. Fresenius Environ. Bull. 13, 501-504.

[12] Coelho, A.; Castro, A.V.; Dezotti, M.; Sant'Anna, G.L. Treatment of petroleum refinery sourwater by advanced oxidation processes. J. Hazard. Mater. 2006, B137, 178184.

[13] Galvao, S.A.O.; Mota, A.L.N.; Silva, D.N.; Moraes, J.E.F.; Nascimento, C.A.O.; ChiavoneFilho, O. Application of the Photo- Fenton process to the treatment of wastewaters contaminated with diesel. Sci. Total Environ. 2006, 367, 42-49.

[14] Tony, M.A., Purcell, P.J. Zhao, Y. Q., Tayeb, A.M., Sherbiny, M.F., Photo-catalytic degradation of an oil-water emulsion using the photo-Fenton treatment process: Effects and statistical optimization, Journal of Environmental Science and Health Part A, 2009 44, 179-187

[15] Bressan, M., Llibratore, L., D’alessandro, N., Tonucci, L., Belli, C., Ranalli, G., Improved Combined Chemical and Biological Treatments of Olive Oil Mill Wastewaters, J. Agric. Food Chem., 52, 2004, 1228-1233.

[16] Dincer, A.R., Karakaya, N., Gunes, E., Gunes, Y., Removal of COD from oil recovery industry wastewater by the advanced oxidation processes (AOP) based on $\mathrm{H}_{2} \mathrm{O}_{2}$, Global NEST Journal, 10 (1), 2008, 31-38.

[17] El-Mashad, H.M., Loon, W.K.P., Zeeman, G., A Model of Solar Energy Utilisation in the Anaerobic Digestion of Cattle Manure, Biosystems Eng., 84 (2), 2003, 231-238.
[18] Khattab, N.M., El Shenawy, E.T., Optimal operation of thermoelectric cooler driven by solar thermoelectric generator, Energy Conversation Manag., 47, 2006, 407-426.

[19] Montgomery, D.C., 1991. Design and Analysis of Experiments. John Wiley, New York.

[20] SAS, 1990. SAS /STAT User's Guide. SAS Institute, Inc., Cary, NC.

[21] Frusteri, F.; Spadaro, L.; Beatrice, C.; Guido C. Oxygenated additives production for diesel engine emission improvement, Chem. Eng. J. 2007, 134, 239-245.

[22] Doong, R., Chang, W., Photoassisted iron compound catalytic degradation of organophosphorous pesticides with hydrogen peroxide. Chemosphere 13, 1998, 2563-2572.

[23] Al Momani, F. A., Ahmad T. Shawaqfeh, Mo'ayyed S. Shawaqfeh, Solar wastewater treatment plant for aqueous solution of pesticide, Solar Energy 81, 2007, 1213-1218.

[24] Sedlak, D.L., Andren, A.W., Oxidation of chlorobenzene with Fenton's reagent, Environ. Sci. Technol., 25, 1991, 777-782.

[25] Lin, S.H., Peng, C.F., Treatment of textile wastewater by Fenton's reagent, J. Environ. Sci. Heal. A30, 1995, 89-98.

[26] Kang, Y.W., Hwang, K.Y., Effects of reaction conditions on the oxidation efficiency in the Fenton process, Water Res., 34, 2000, 27862790.

[27] Prabhakaran, D., Kannadasan, T., Ahmed Basha, C., Treatability of resin effluents by electrochemical oxidation using batch recirculation reactor, Int. J. Environ. Sci. Tech., 6 (3), 2009, 491-498.

[28] Safarzadeh-Amiri, A., Bolton, J.R., Cater, S.R., Ferrioxalate mediated solar degradation of organic contaminants in water, Solar Energy, 56 (5), 1996, 439-443. 